\section{Autoantikörper gegen Elastin}

W. Stöcker

Euroimmun Medizinische Labordiagnostika AG, Lübeck, Deutschland

\section{Synonym(e) Elastin-Autoantikörper}

Englischer Begriff elastin reactive autoantibodies

Definition Sammelbezeichnung für Autoantikörper, die gegen Tropoelastin, Elastinfasern und deren Abbauprodukte $(\alpha$-Elastin) gerichtet sind.

Funktion - Pathophysiologie Die Degeneration von Elastinfasern wird als eine mögliche Ursache von Gefäßschäden diskutiert. Eine Beteiligung von Autoantikörpern gegen Elastin an der Pathogenese verschiedener Formen der Vaskulitis konnte bisher nicht nachgewiesen werden.

Untersuchungsmaterial Serum oder Plasma.

Probenstabilität Autoantikörper sind bei $+4{ }^{\circ} \mathrm{C}$ bis zu 2 Wochen lang beständig, bei $-20^{\circ} \mathrm{C}$ über Monate und Jahre hinweg.

Analytik $>$ Enzyme-linked Immunosorbent Assay, indirekter Immunfluoreszenztest ( $\triangleright$ Immunfluoreszenz, indirekte).

Referenzbereich - Erwachsene Nicht bekannt.

Referenzbereich - Kinder Nicht bekannt.
Indikation Vaskulitis, $5 \%$ bei multipler Sklerose.

Interpretation Autoantikörper gegen Elastin zeigen in der Immunfluoreszenz auf Arterienschnitten eine typische wellenförmige Anfärbung der Laminae elastica interna und externa (s. Abbildung).

Autoantikörper gegen Elastin, indirekte Immunfluoreszenz mit Substrat Rattenniere:

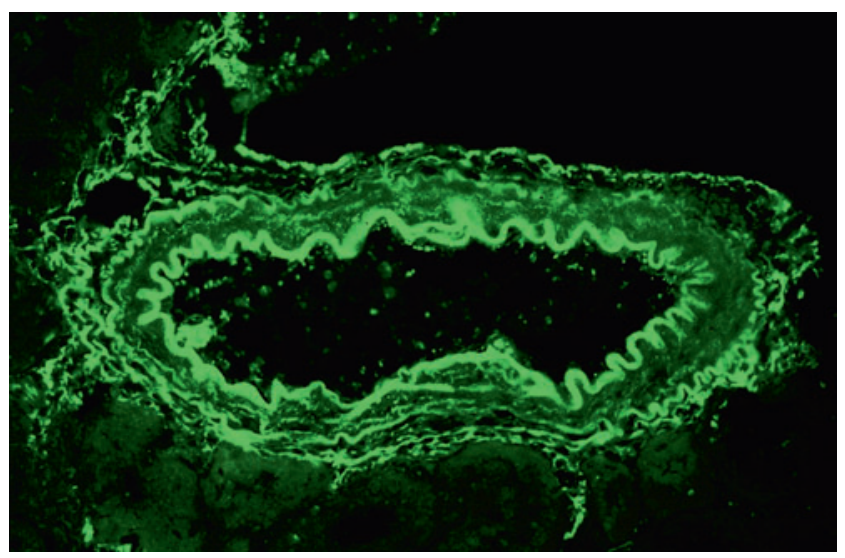

Die Untersuchung der Autoantikörper gegen Elastin ist bisher allenfalls wissenschaftlichen Fragestellungen vorbehalten.

\section{Literatur}

Colburn KK, Langga-Shariffi E, Kelly GT, Malto MC, Sandberg LB, Baydanoff S, Green LM (2003) Abnormalities of serum antielastin antibodies in connective tissue diseases. J Investig Med Mar 51:104-109 